\title{
STRUCTURAL TORSIONAL RESPONSE BEHAVIOR AND PREDICTION FOR STEEL FIBER-RECYCLED AGGREGATE CONCRETE BEAMS
}

\author{
Mazin A. Ahmed ${ }^{1}$, * Aqeel H. Chkheiwer ${ }^{2}$ and Alyaa Alhamaidah ${ }^{3}$ \\ 1,2,3 Engineering Collage, University of Basrah, Iraq
}

*Corresponding Author, Received: 07 June 2021, Revised: 02 Oct. 2021, Accepted: 17 Oct. 2021

\begin{abstract}
A torsional response evaluation of horizontal structural members considers the most complex issues faced by structural members such as beams. The purpose of this research is to determine the structural response of steel fiber-recycled aggregate concrete beams under torsional effects. Torsion tests are performed on twenty reinforced steel fiber concrete samples with recycled aggregates, and supplementary tests are conducted on steel fiber concrete with recycled concrete in direct tension and fiber pullout tests. The main parameters of this research were the percentages of steel fibers and recycled aggregate. The torsional response and crack behavior of the beams were investigated. It was discovered that a beam reinforced with steel fiber and natural aggregate has a lower torsional response and a higher energy absorption capability than a beam with recycled aggregate and that a recycled beam has a lower ductility than a beam with natural aggregate.
\end{abstract}

Keywords: Torsion, Recycled concrete beam, Steel fiber, Crack, Ductility

\section{INTRODUCTION}

The addition of steel fibers to concrete mixes improves the mechanical properties and reinforced concrete tensile strength and controls crack propagation [1-3]. It increases tensile stress on crack surfaces because the fibers are capable of forming a crack bridge and have considerable resistance to shear across cracks. To achieve cracking, steel fibers require deboning and removal from the concrete. As a result, concrete with steel fibers has a pseudo-ductile tensile reaction and a higher potential for energy dissipation than brittle concrete with steel fibers [4, 5]

Steel fibers may substitute for a portion of traditional steel reinforcement, primarily stirrups, particularly where design requirements call for a high steel content [8]. Studies involving the addition of steel fibers to concrete with various aspect ratios and volume contents provide stressstrain curves matching to test specimens. In the diagrams, ductility under constant stress rises as the volume content of the fiber increases. In other words, there is no change up to the crack, but ductility improves as the content of steel fibers increases [9, 10]. When the unit angle of twist of the unreinforced normal strength concrete beams falls between 0.002 and $0.003 \mathrm{rad} / \mathrm{m}$, they achieve their ultimate torsional capacity. When fiber reinforcement is used in concrete, the unit angle of the twist increases to $0.006-0.007$ rad $\mathrm{m}$ [11]. Steel fibers in a concrete blend increase the torsional strength of the beam by improving the strength of the concrete [12-16]. Fiberreinforcement of concrete has the drawback of affecting the workability, especially in the case of steel fiber-reinforced concrete. Even dispersion of fibers throughout your concrete is an issue. There is also the possibility of fibers balling up during the mixing process. Another disadvantage to be aware of is the weight difference between fiberreinforced and nonfiber concrete. If steel fibers are utilized, rusting may occur. Finally, fiberreinforced concrete is more expensive than regular concrete; however, this difference may be mitigated by other factors. A part of the usual aggregates is replaced with recycled aggregates in the concrete mix. Recycled aggregate consists of hard, angular and elongated particle sympathy and smooth and compact rounding aggregates. The characteristics of the recycled aggregate vary according to the physical and chemical properties of the sources. Recycled concrete is less dense and strong than natural aggregates $[17,18]$. Because some of the weaker mortar attached to the original aggregates is lost in the process, the best size distribution and form are produced when the materials are crushed using a jaw crusher and subsequently a rotary crusher (primary and secondary crushing) [19]. The presence of mortar from the source concrete in the recycled aggregates gives the recycled aggregates a rougher and more porous texture and improves the recycled aggregate imbrication action with the fresh mortar. The water absorption by recycled aggregate 
increases with an increase in the strength of the parent concrete from which the recycled aggregate is derived but decreases with an increase in the maximum size of the aggregate [20]. In the concrete waste combinations, the specific gravity was lower than in the usual crushed combinations $[21,22]$.

From the studies mentioned above, it can be observed that there is a lack of information about the effect of steel fibers on the torsional strength of recycled aggregate concrete, and no theoretical relationship has been found to explain the torquetwist angle relation for fiber-reinforced recycled aggregate concrete.

This study aims to investigate the contribution of steel fiber to the torsional strength and behavior of recycled aggregate concrete and adopts a theoretical approach for normal concrete to apply it to fiber recycled aggregate concrete depending on the Hsu softened body model [23].

\section{PREDICTION OF THE TORSIONAL RESPONSE}

The space model was reformulated in simple form to provide a ready reference to the required modifications of inclusive fiber in the control equations extracted from equilibrium, consistency and constitutive relationships for the pure torsion of Hsu [23].

\subsection{Equilibrium equations}

The equilibrium equations that rolled the torsion issue are listed below:

$$
\begin{aligned}
& \sigma_{t}=\sigma_{d} \cos ^{2} \alpha+\sigma_{r} \sin ^{2} \alpha+\rho_{t} f_{t}=0 \\
& \sigma_{l}=\sigma_{d} \sin ^{2} \alpha+\sigma_{r} \cos ^{2} \alpha+\rho_{l} f_{t}=0 \\
& \tau_{l t}=\left(\sigma_{d}-\sigma_{r}\right) \sin \alpha \cdot \cos \alpha \\
& \tau_{l t}=T /\left(2 A_{o} t_{e}\right)
\end{aligned}
$$

where $\alpha$ is the average normal stress, $\tau$ is the average shear stress, $\rho$ is the ratio of reinforcement, $\mathrm{f}$ is the stress of steel, $\mathrm{T}$ is the applied torque, $\mathrm{t}_{\mathrm{e}}$ is the effective wall thickness, $A_{0}$ is the region surrounded by the path of shear flow, $\alpha$ is the crack inclination, and subscripts $\mathrm{l}, \mathrm{t}$ and $\mathrm{d}, \mathrm{r}$ indicate the direction of orthogonal coordinates for the wall of the element, as shown in Fig.1.

\subsection{Compatibility Equations}

The compatibility equations that rolled the torsion issue are listed below:

$$
\begin{aligned}
& \epsilon_{t}=\epsilon_{d} \cos ^{2} \alpha+\epsilon_{r} \sin ^{2} \alpha \\
& \epsilon_{l}=\epsilon_{d} \sin ^{2} \alpha+\epsilon_{r} \cos ^{2} \alpha \\
& \gamma_{l t}=2\left(\epsilon_{d}-\epsilon_{r}\right) \sin \alpha \cos \alpha \\
& \theta=p_{o} \gamma_{l t} / 2 A_{o} \\
& \psi=\theta \cdot \sin 2 \alpha \\
& t_{e}=\epsilon_{d m} / \psi \\
& \epsilon_{d}=\epsilon_{d m} / 2
\end{aligned}
$$

where $\varepsilon$ is the average normal strain, $\gamma$ is the average shear strain, $\varepsilon_{d m}$ is the maximum strain at the concrete surface, $\theta$ is the angle of twist, $\psi$ is the curvature of the concrete struts and $P_{o}$ is the perimeter of the shear flow path.

\subsection{Constitutive Relationships}

The constitutive relation of Steel is specified in Equation 12 and Equation 13.

$\mathrm{f}_{\mathrm{t}}=\left(\mathrm{f}_{\mathrm{y}}\right)_{\mathrm{t}} \quad \epsilon_{t} \geq\left(\epsilon_{y}\right)_{t}$

$\mathrm{f}_{\mathrm{t}}=\mathrm{E}_{\mathrm{s}} \epsilon_{t} \quad \epsilon_{t}<\left(\epsilon_{y}\right)_{t}$

$\mathrm{f}_{\mathrm{t}}=\left(\mathrm{f}_{\mathrm{y}}\right)_{\mathrm{l}} \quad \epsilon_{l} \geq\left(\epsilon_{y}\right)_{l}$

$\mathrm{f}_{\mathrm{l}}=\mathrm{E}_{\mathrm{s}} \epsilon_{r} \quad \epsilon_{l}<\left(\epsilon_{y}\right)_{l}$

where $f_{y}, \epsilon_{y}$ and Es are the yield stress, yield strain and modulus of elasticity of the steel bars. The constitutive relationship of Concrete rolled by Equation 14 to Equation 16 in compression and Equation 17 for tension.

\subsection{Compression response}

$\sigma_{d}=K_{1} \frac{1}{\lambda} \hat{f}_{c}$

$\lambda=\sqrt{0.7-\epsilon_{r} / \epsilon_{d}}$

$K_{1}=\lambda \frac{\epsilon_{d m}}{\epsilon_{o}}-\frac{\lambda^{2}}{3}\left(\frac{\epsilon_{d m}}{\epsilon_{o}}\right)^{2}$ 


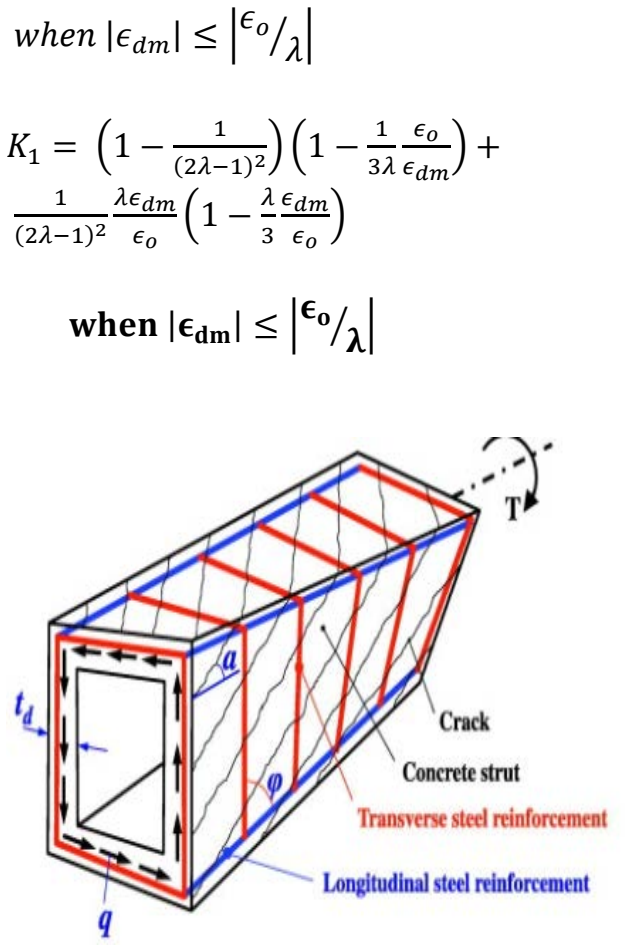

Fig. 1 Orthogonal coordinates directions for wall of the element.

where $\varepsilon_{0}$ is the strain of concrete at maximum stress for non-softened concrete, which is taken as -0.002, and $f{ }^{\prime} C$ is the cylinder compression strength.

\subsection{Tension response}

The tension response rolled by the Equation 17.

$$
\begin{array}{ll}
\sigma_{\mathrm{r}}=\mathrm{E}_{\mathrm{c}} \epsilon_{r} & \text { when } \epsilon_{r} \leq \epsilon_{c r} \\
\sigma_{\mathrm{r}}=0 & \text { when } \epsilon_{r}>\epsilon_{c r}
\end{array}
$$

where $\epsilon_{c r}$ cracks a concrete strain into a stress of a direction and $E_{c}$ becomes a concrete elasticity modulus. The ratio of Equations 14 to 16 in this analysis is supposed to be true for fibrous concrete and $f{ }^{\prime} c$ for fibrous concrete. The literature indicates a typical stress curve for directly tense fibrous concrete [24]. The curves are similar in the initial straight part before cracking, although the fiber quality of the post cracking action is different. The overall tension depends on the thickness of the concrete and on the percentage of fibers. In this analysis, the stress-strain curve was used, but when the truss triggered a rigid plastic stress-strain connection in the reinforcement cement beam after cracking, it was represented by: $\sigma_{\mathrm{r}}=\sigma_{\mathrm{tu}}$

$\sigma_{\mathrm{tu}}=\eta_{\mathrm{t}} \eta_{\mathrm{o}} \mathrm{V}_{\mathrm{f}}^{l_{f}} \frac{l_{f}}{u}$

where $\eta t$ is length efficiency factor, $\eta o$ is orientation factor for the fiber, $V_{f}$ is volume fraction of fiber, $l_{f}$ is fiber length, $r$ is ratio of fiber cross section to its perimeter and $T_{u}$ is ultimate bond strength of fiber. $\eta o$ depends on the critical length $l_{c}$ of fiber. If failure occurs by fiber pullout, then $\eta t=0.5$. $\eta o$ depends on the distribution of fibers and was varied between 0.33 and 0.5 . Therefore, otu can be calculated from Equation 19 as long as $T_{u}$ is known.

Substituting Equations 12, 5, 11 and 18 into Equation 1 yields:

$\cos ^{2} \alpha=\frac{-\left(\sigma_{t u}+\rho_{l}\left(f_{y}\right)_{t}\right)}{\sigma_{d}-\sigma_{t u}} \quad \epsilon_{t} \geq\left(\epsilon_{y}\right)_{t}$

$\cos ^{2} \alpha=\frac{-\left(\sigma_{t u}+\rho_{l} E_{s} \epsilon_{r}\right)}{\sigma_{d^{-}} \sigma_{t u}-\rho_{l} E_{s}\left(\epsilon_{r^{-}} \epsilon_{d m} / 2\right)} \epsilon_{t}<\left(\epsilon_{y}\right)_{t}$

Substituting with Equations 13, 6, 11 and 19 yields:

$\epsilon_{r}=\frac{-\left(2 \sigma_{d}+\rho_{t} E_{s} \epsilon_{d m}\right)}{2 \rho_{t} E_{s}} \tan ^{2} \alpha-\frac{\sigma_{t u}}{\rho_{l} E_{s}}$

when $\epsilon_{t}<\left(\epsilon_{y}\right)_{t}$

When $\epsilon_{t}>\left(\epsilon_{y}\right)_{t}$, Eq. 12 must be satisfied.

$\rho_{t}=A_{t} / \mathrm{P}_{o} t_{o}$

$\rho_{l}=A_{l} / S t_{e}$

where $A_{t}$ is the total amount of longitudinal steel and $A_{l}$ is the area of one leg of stirrup $s$ is the stirrup spacing.

\section{TEST SCENARIO}

The experimental work included testing 20 beams with and without recycled aggregates in pure torsion and direct stress on fibrous concrete.

\subsection{Beams Tested}

Table (1) showing the details of the checked beams. All beams had a similar cross section of $300 \times 300 \mathrm{~mm}$ and a length of $2.5 \mathrm{~m}$. All tested beams had equal longitudinal and transverse 
reinforcement. The proportion of steel fibers and recycled aggregate are the most important variables. Fig. 2 depicts the specifics of the checked beams.

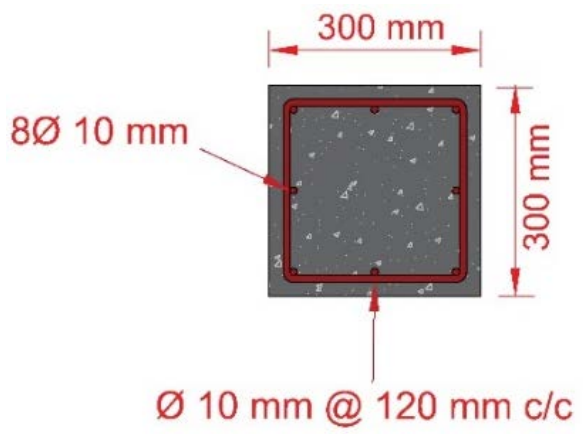

Fig. 2 Detail of tested beams.

In longitudinal and transverse strengthening, 10 $\mathrm{mm}$ deformed bars were used. The average capacity and elasticity modulus were $410 \mathrm{~N} / \mathrm{mm} 2$ and $2.04 \mathrm{X} 105 \mathrm{~N} / \mathrm{mm} 2$, respectively. The steel fibers used in all beams were straight and slightly twisted in the experimental scenario.

In these samples, recycled concrete aggregates were collected from the removal of concrete cubes brought for testing in the laboratory where B.S 882-1983 was graded [25]. This aggregate had an overall scale of $20 \mathrm{~mm}$. During the whole investigation, the same concrete mix was used. It was made of 1.0, 1.2, 2 and $0.45 \%$ concrete, sand, gravel and w/c ratio with a compression power of cubic above $30 \mathrm{~N} / \mathrm{mm}$. The first was made of natural gravel as coarse and natural silica sand as fine added. It was made of three types of concrete combinations. The second blend was produced by applying steel fibers to the concrete, and the third blend was produced by means of reclaimed concrete aggregates with a distinct substitution mixture of raw aggregates and natural silica sand as fine aggregates.

The Universal Test Engine Model (8551 MFL) was used to test all beams in the form of a maximum power of 300 tons, as shown in Fig.3. At either end with a direct stretch of $2100 \mathrm{~mm}$, the beams are mounted in the process on free assisted rollers. The concrete beam was connected to two pieces of steel strengthened by a tapped plate acting as lever arms. The University of Basrah/Concrete Lab Engineering College has all the equipment and accessories needed to manufacture and test validated beams. A collection of linear usable displacement transducer axes (LVDTs) was calculated to quantify torsional rotations. Three $10 \mathrm{~mm}$ long electric strength stress gauges were mounted on one corner longitudinal bar at a space of $50 \mathrm{~mm}$, and the longitudinal strain $\varepsilon_{1}$ of the TOL was registered. Three electrical resistance strain gauges with a gage length of $30 \mathrm{~mm}$ were used to measure the diagonal concrete strain $\varepsilon_{\mathrm{dm}}$. The gauges were placed on the surface of the beam at an inclination angle of $45 \mathrm{deg}$ at the mid depth of the beam axis. On one of the vertical faces of the beam, in the tested zone, the number of cracks was recorded, and their widths were measured by a handheld microscope with an accuracy of $\pm 0.001 \mathrm{~mm}$.

Table 1 Beam details

\begin{tabular}{|c|c|c|c|c|}
\hline 灾 & 苂 & $\begin{array}{c}\text { Steel } \\
\text { fibers } \\
\% \\
\end{array}$ & $\begin{array}{c}* \mathrm{RA} \\
\%\end{array}$ & $\begin{array}{c}* * \mathrm{fcu}_{\mathrm{cu}} \\
\mathrm{N} / \mathrm{mm}^{2}\end{array}$ \\
\hline \multirow{5}{*}{ A } & B1 & Without & Without & 30 \\
\hline & B2 & Without & 25 & 28 \\
\hline & B3 & Without & 50 & 26 \\
\hline & B4 & Without & 75 & 26 \\
\hline & B5 & Without & 100 & 25 \\
\hline \multirow{5}{*}{ B } & B6 & 0.5 & Without & 32 \\
\hline & B7 & 0.5 & 25 & 30 \\
\hline & B8 & 0.5 & 50 & 28 \\
\hline & B9 & 0.5 & 75 & 27 \\
\hline & $\mathrm{B} 10$ & 0.5 & 100 & 27 \\
\hline \multirow{5}{*}{$\mathrm{C}$} & B11 & 1.0 & Without & 35 \\
\hline & B12 & 1.0 & 25 & 34 \\
\hline & B13 & 1.0 & 50 & 30 \\
\hline & B14 & 1.0 & 75 & 28 \\
\hline & B15 & 1.0 & 100 & 27 \\
\hline \multirow{5}{*}{$\mathrm{D}$} & $\mathrm{B} 16$ & 1.5 & Without & 37 \\
\hline & B17 & 1.5 & 25 & 34 \\
\hline & B18 & 1.5 & 50 & 34 \\
\hline & B19 & 1.5 & 75 & 31 \\
\hline & B20 & 1.5 & 100 & 28 \\
\hline
\end{tabular}

*RA: recycled aggregate

**fcu: cube compressive strength

\subsection{Tension Test}

To estimate the critical advantage of $\sigma_{\mathrm{lu}}$ in the anticipated relationship of stress-strain, three specimens of concrete to each percent of steel fiber and recycled aggregate were assessed in direct stress. The Tu value was determined by testing 60x60x300 mm prisms. Relatively vulnerable cracks were formed by 2 triangular, $5 \mathrm{~mm}$ deep grooves on both sides of the medium specimens. A particular type of adhesive was used to attach the specimens to a stain plate on either end. 


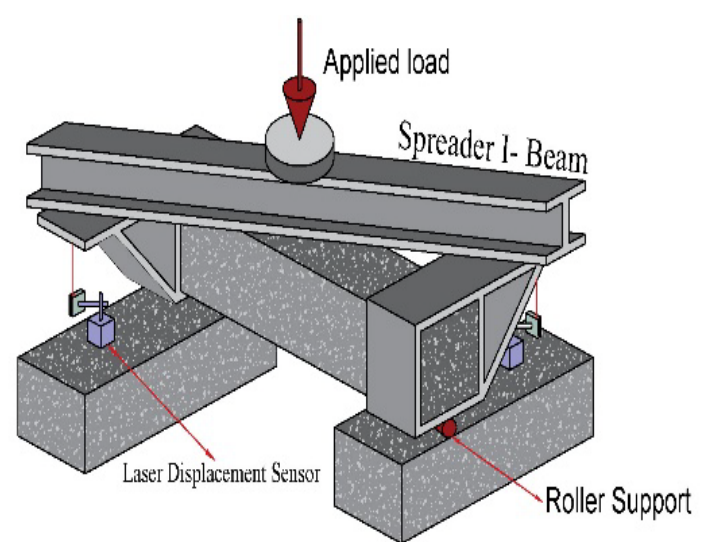

Fig. 3 Test setup for the beams.

\subsection{Fiber Pullout Test}

Specifically, the tensile response of concrete containing fibers is dependent on the interface bond strength, and the latter is dependent on the strength of the concrete. In this study, pullout tests determined this fundamental property. The first vertically implanted individual fibers were picked at random. During subsequent handling, this small piece was to withstand any involuntary disruptions. Depending on the length of the embedding needed, the length of the fibers outside the plate was different, and the fibers were spaced out of each other $30 \mathrm{~mm}$. The polystyrene tubes, each with two embedded fibers, were then placed into prism molds measuring 100x100x400 mm. Concrete mix was poured into the mold and compacted by a vibrator. Then, the polystyrene layer was carefully raised and spray coated on the fiber-free ends to prevent rusting and to provide an extra examination of the length of steel fiber embedment before returning the specimen for eventual curing. The specimen was fixed in a machine, and fibers were drawn by a universal joint using an accurate drill bit possessor.

\section{EXPERIMENTAL RESULTS}

The experimental findings obtained from the checked beams are tabulated in Tables (2 and 3), which include cracking torque (Tcr). This value reflects the load received as the first crack occurs on the surface of the beam. The measure will also have ultimate torque (Tu), which reflects the highest value, as well as the angle of twisting for checked beams.

B1, B2, B3, B4, and B5 (Group A), Fig. 4, reflect beams without steel fiber and can be used to investigate the effect of recycled aggregates. This group yields Tcr and Tu values of $(65,71,75,82$, 90) and (70, 75, 78, 88, 95), respectively, indicating that raising the ratio of recycled aggregate decreased the torque strength of the beam and yielded a lower value of Tcr. This activity is consistent with all beam classes. It should also be remembered that the percentage decrease is roughly equal for both races. It can be inferred that the use of steel fiber has no impact on the percentage decrease in $\mathrm{Tcr}$ and $\mathrm{Tu}$ when recycled aggregate is used in the beam. Furthermore, the magnitude of ultimate torsion for beams with steel fiber is greater than the equivalent value for beams without steel fiber, and rising steel fiber produces an increase in Tu.

Table 2 Summary of the test results

\begin{tabular}{ccccc}
\hline \multirow{2}{*}{ Beam } & \multicolumn{2}{c}{ Torque $(\mathrm{kNm})$} & \multicolumn{2}{c}{ Twist Deg./m } \\
\cline { 2 - 5 } & Tcr & Tu & $\theta \mathrm{cr}$ & $\theta \mathrm{u}$ \\
\hline B1 & 90 & 95 & 1.26 & 2.08 \\
\hline B2 & 82 & 88 & 1.11 & 1.90 \\
\hline B3 & 75 & 78 & 0.95 & 1.82 \\
\hline B4 & 71 & 75 & 0.60 & 1.00 \\
\hline B5 & 60 & 70 & 0.41 & 0.78 \\
\hline B6 & 106 & 114 & 1.05 & 2.56 \\
\hline B7 & 100 & 103 & 0.92 & 2.41 \\
\hline B8 & 95 & 98 & 0.84 & 1.81 \\
\hline B9 & 87 & 95 & 0.44 & 1.14 \\
\hline B10 & 80 & 88 & 0.32 & 0.88 \\
\hline B11 & 123 & 133 & 0.76 & 3.67 \\
\hline B12 & 118 & 125 & 0.61 & 3.11 \\
\hline B13 & 106 & 114 & 0.55 & 2.45 \\
\hline B14 & 102 & 111 & 0.31 & 2.14 \\
\hline B15 & 90 & 105 & 0.28 & 1.36 \\
\hline B16 & 138 & 147 & 0.38 & 4.45 \\
\hline B17 & 125 & 133 & 0.30 & 4.02 \\
\hline B18 & 114 & 122 & 0.27 & 3.05 \\
\hline B19 & 106 & 117 & 0.22 & 2.24 \\
\hline B20 & 95 & 115 & 0.17 & 1.42 \\
\hline & & & &
\end{tabular}

The effect of steel fiber varies depending on the proportion of recycled aggregate used; for example, in beams B1, B6, B11, and B16 with steel fiber levels of $0,0.5,1$, and 1.5 (with natural aggregate), increasing the amount of steel fiber results in $\mathrm{Tu}$ increases of 20, 40, and 55\%, respectively. 


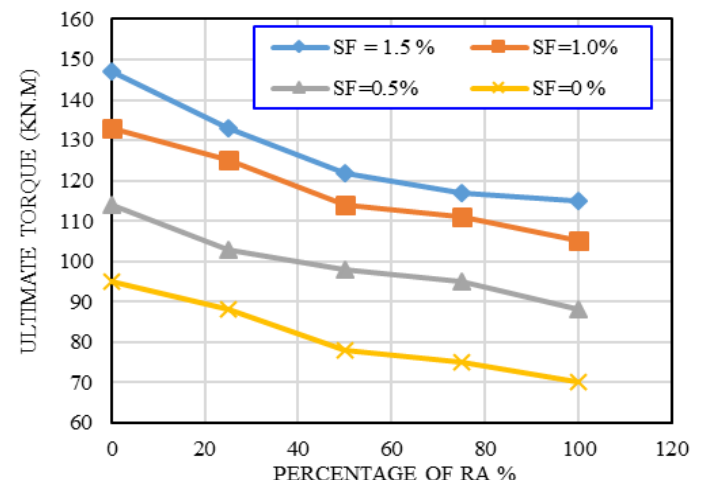

Fig. 4 Graph of the test results

Table 3 Summary of the percentage results for loading and twisting

\begin{tabular}{|c|c|c|}
\hline Beam & $\operatorname{Tcri} /(\operatorname{Tcr} B 1)$. & Tui/(Tu B1. $)$ \\
\hline B1 & --- & ---- \\
\hline B6 & 1.17 & 1.20 \\
\hline B11 & 1.36 & 1.40 \\
\hline \multirow[t]{2}{*}{ B16 } & 1.44 & 1.55 \\
\hline & $(\boldsymbol{T c r i}) /(\operatorname{Tcr} B 2)$ & $(\boldsymbol{T u} i) /(\boldsymbol{T u} B 2)$ \\
\hline $\mathrm{B} 2$ & ---- & ---- \\
\hline B7 & 1.22 & 1.08 \\
\hline B12 & 1.44 & 1.42 \\
\hline \multirow[t]{2}{*}{ B17 } & 1.52 & 1.51 \\
\hline & $\begin{array}{l}(\operatorname{Tcr} i) \\
/(\operatorname{Tcr} B 3)\end{array}$ & $(\boldsymbol{T u} \boldsymbol{i}) /(\boldsymbol{T} \boldsymbol{u} B \mathbf{3})$ \\
\hline B3 & --- & ---- \\
\hline B8 & 1.27 & 1.25 \\
\hline $\mathrm{B} 13$ & 1.41 & 1.46 \\
\hline \multirow[t]{2}{*}{$\mathrm{B} 18$} & 1.52 & 1.56 \\
\hline & $\begin{array}{l}\text { Tcr } \\
/(\text { Tcr cont. })\end{array}$ & $\begin{array}{l}\text { Tcr } \\
/(\text { Tcr cont })\end{array}$ \\
\hline B4 & --- & --- \\
\hline B9 & 1.22 & 1.27 \\
\hline B14 & 1.43 & 1.48 \\
\hline \multirow[t]{2}{*}{ B19 } & 1.49 & 1.56 \\
\hline & $\begin{array}{l}\text { Tcr } \\
/(\text { Tcr cont } .)\end{array}$ & $\begin{array}{l}\text { Tcr } \\
/(\operatorname{Tcr} \text { cont } .)\end{array}$ \\
\hline B5 & --- & --- \\
\hline $\mathrm{B} 10$ & 1.33 & 1.26 \\
\hline $\mathrm{B} 15$ & 1.50 & 1.50 \\
\hline $\mathrm{B} 20$ & 1.58 & 1.64 \\
\hline
\end{tabular}

When steel fibers with ratios of $0,0.5,1.0$, and 1.5 are used for beams B5, B10, B15, and B20, respectively, with a recycled total of $100 \%$, the $\mathrm{Tu}$ ratio increases by 26, 50 and 64\%, respectively. This happens to be the acute result of steel fiber in concrete, as recycled aggregate is used instead of natural aggregate. Compared with the results of beams B1, B6, B11 and B16, which used 100\% natural aggregates, Tcr increased by $17 \%$, 36\% and $44 \%$ when steel fibers increased from zero to $0.5,1.0$, and 1.5 , but this percentage was largest when $100 \%$ recycled aggregates were used. The ratio of cracking torque increased by 33, 50 and 58 in the B5, B10, B15 and B20 beams, respectively, which confirms the influence of steel fiber.

\section{TORQUE-TWIST RESPONSE}

Figs. 5 and 6 depict the relationships between the applied torques $(\mathrm{T})$ and twist per unit length (deg/m) for commonly tested beams. Generally, for steel fiber beams, the ultimate torque increases, and the conduct of the beams is linear prior to cracking. The hardness of steel fiber beams is greater than that of beams without steel fibers because the stress delivery pattern from the concrete to has an increase in the twist angle without an increasing torque. The beams have a nonlinear response before high loads and a decreasing torsional stress, while the beams are more ductile during the post cracking process. $100 \%$ recycled beams have the same behavior.

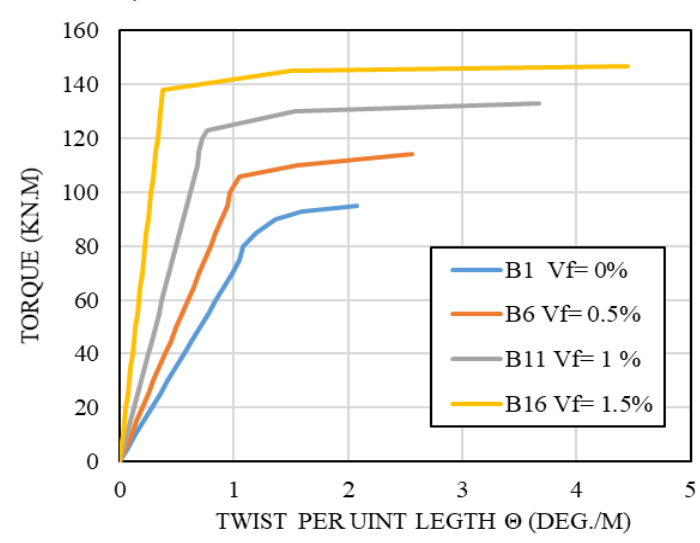

Fig. 5 Experimental torque T-twist response for beams with natural aggregate

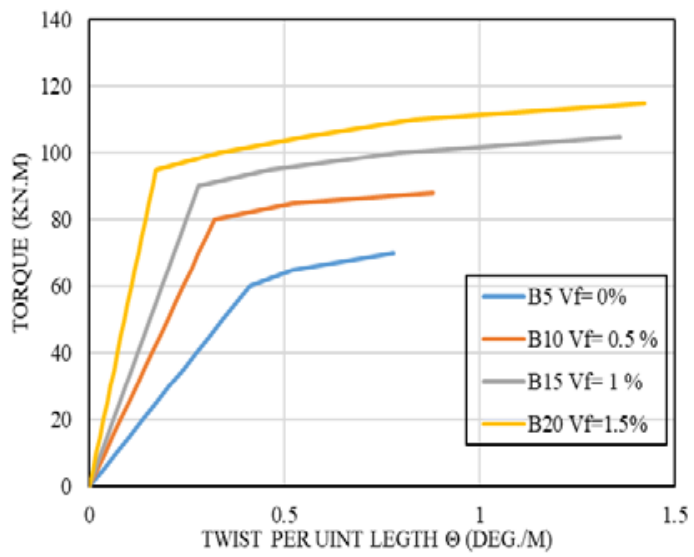

Fig. 6 Experimental torque-twist response for beams with $100 \%$ recycled aggregate. 
Table 1 shows the values of Tcr, Tu, and twisting angle per length unit $\mathrm{cr}$ and $\mathrm{u}$ that correspond to those for all beams (2). The stiffest beam was B16, which comprised 1.5 percent steel fiber and 0 percent recycled aggregate and has Tcr and Tu that are 1.44 and 1.55 , respectively, greater than Tcr and Tu for beam B1. Steel fiber performance was lowest in B5, which contained $0 \%$ steel fiber and $100 \%$ recycled aggregate and had Tcr Tu values similar to control beam B1. Steel fibers increase the stiffness of the beam by reducing the splitting twisting angle $\mathrm{cr}$ as a result, reducing cracking in the concrete, and increasing Tu to 1.55 greater than $\mathrm{B} 1$, which provides tensile tension between the beam and the concrete.

When recycled aggregate is used, the energy absorption capability of the beam will decrease. Comparison of load response for beams B2, B7, B12 and B17 (with 25\% recycled aggregate with different ratios of steel fibers $0,0.5,1.0$ and 1.5, respectively) shows that steel fiber contributed to increasing $T_{\text {cr }}$ and post cracking stiffness as well torsional strength $(\mathrm{Tu})$. Beams in Groups C and B, which used different ratios of steel fiber with different percentages of recycled aggregate of 50 and $75 \%$, respectively, showed that increasing the steel fiber caused an increase in $T_{c r}, T_{u}$ and post cracking stiffness, but this increase decreased with increasing recycled aggregate.

\section{MODE OF FAILURE}

The mode failure of the tested beams is depicted in Fig. 7. Beam B1 (control beam) exhibits standard torsion failure behavior, with spiral diagonal cracks noted continuous across the cross section of the beam with a crack angle of approximately $45^{\circ}$ according to the longitudinal axis of the beam. After the load increased, the concrete crushed in the center of the beam, and this load caused the beam to fail. This is comparable to the action of beams devoid of steel fiber (B2, B3, B4 and B5). Beams with steel fiber, on the other hand, fail in a different way, particularly those with a high percentage of steel fiber of 1.5 percent (B16, B17, B18, B19, and B20). The key advantage of steel fiber is that it can be used to create a crack-control system that prevents

Pseudo-ductility in post-cracking action. The figure increase in the beam primary cracking strength is called a secondary effect of steel fiber, and it is proportional to the percentage of steel fiber in the concrete blend. For a low percentage of steel fiber, the improvement of primary cracking was slight, and the improvement of the first cracking and $T_{u}$ depended upon the recycled aggregate, which caused them to be clearly improved.

From Fig. 8, it can be noted that at the same torque, the beams with $100 \%$ recycled aggregate (B5 and B20) exhibited crack widths greater than beams with natural aggregate (B1 and B16). In addition, the beams with $1.5 \%$ steel fibers had smaller crack widths than the beams without fibers (B1 and B5). The crack width decreases as steel fiber is applied to a concrete blend. This may be attributed to steel fibers forming bridges between concrete fragments, reducing the crack diameter.

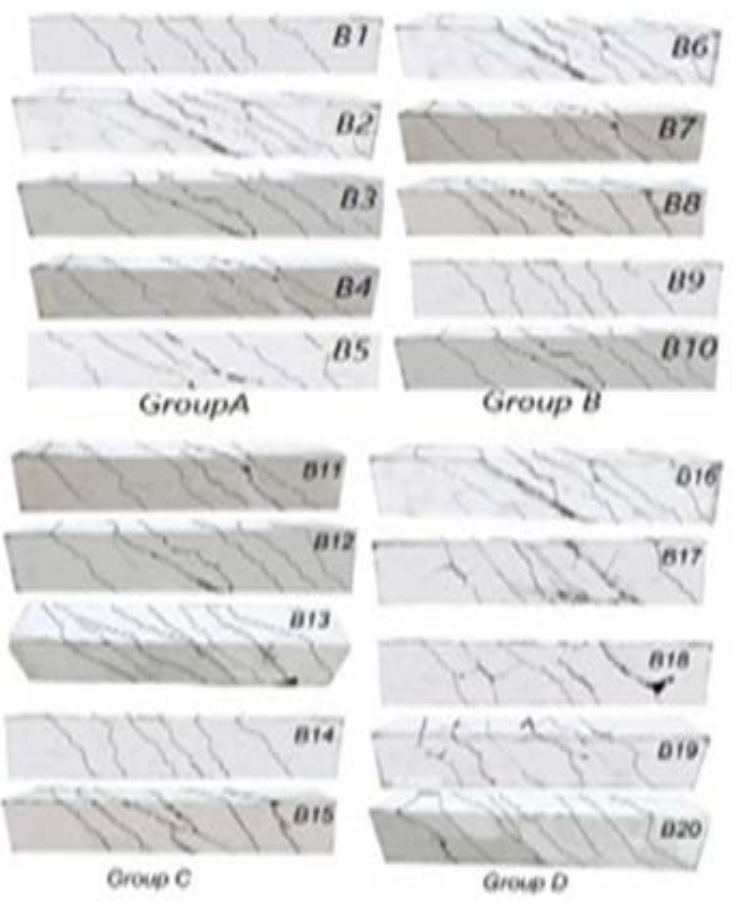

Fig. 7 Mode of Failure

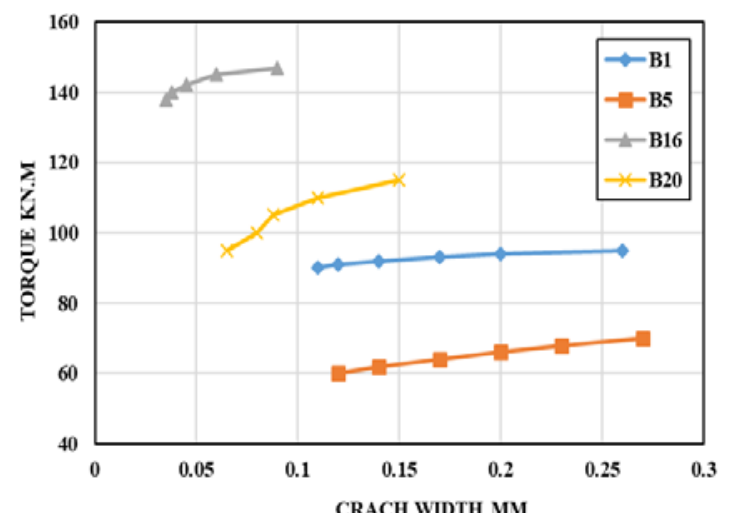

Fig. 8 Effect of steel fiber and recycled aggregate on cracks 
To investigate the stress-strain relationships, three specimens were examined under direct tension for each percent of steel fiber; Fig. 9 depicts the average curves of the specimens. It is clearly noted that the relationship was linear prior to the occurrence of cracks. Following that, the load would abruptly decrease. Suddenly with particular increases in the strain. The dashed line in Fig.9 represents the region that cannot be measured because the crack causes sudden localized distortion. After that, deformation of the specimens continued at approximately the same level of the load up to the attention domain (width of crack $1 \mathrm{~mm}$ ). Fig. 9 shows the post cracking tensile strength, which increased with increasing steel fiber content. The torque twist for Group A (B1 and B5) was between those of concrete with normal aggregate (recycled aggregate, $0 \%$ ) and Group D (B16 and B20). The percentages for $100 \%$ recycled aggregate and steel fiber were 0 and 1.5, respectively. The figures show that the curves were different through the first stage of loading then the curves converge after cracking

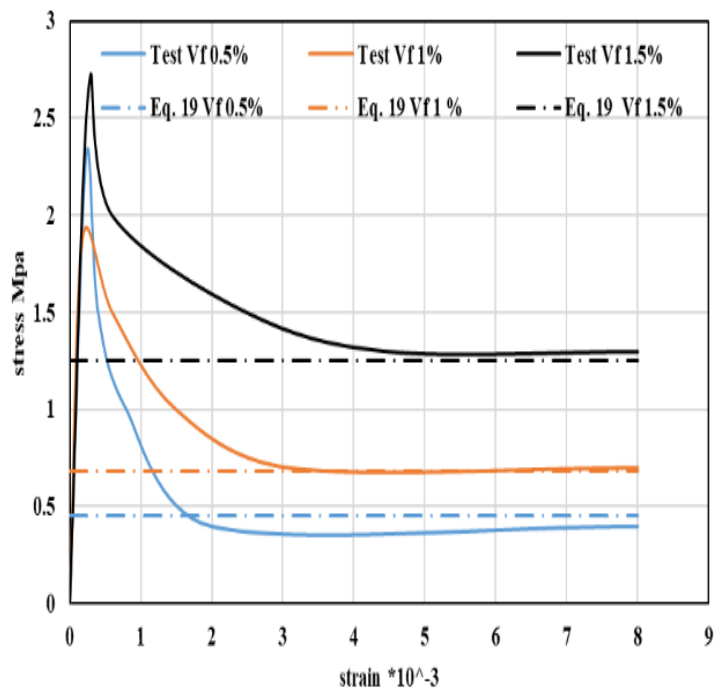

Fig. 9 Stress-strain curves of the tensile test for the prism

Pullout was measured on concrete of steel fiber, with three specimens of varying percentages of steel fiber: 0.5, 1.0, and 1.5. Figs. 10, 11, and 12 display the effects. The relationship between the pullout load and surface area of the embedded fibers was nearly linear. Linear regression analysis was used to calculate the slope of the best-fit linear model, which shows the ultimate bond strength $\mathrm{Tu}$ for each batch of concrete, and its value is shown in Figs. (10 to 12).

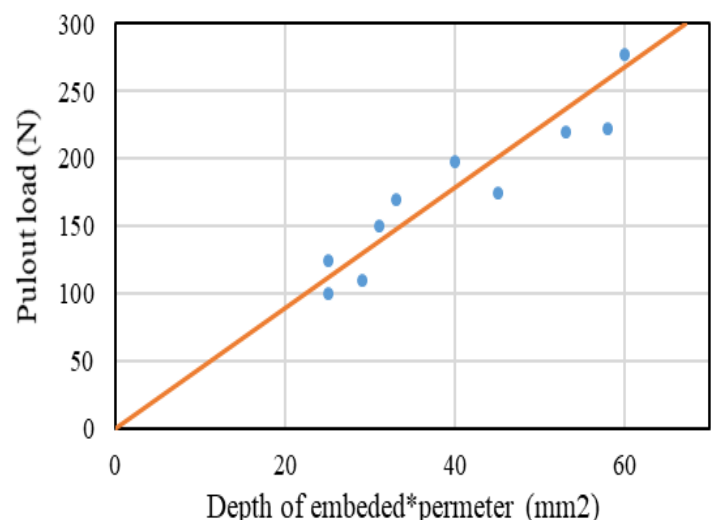

Fig. 10 Concrete with $0.5 \%$ steel fiber

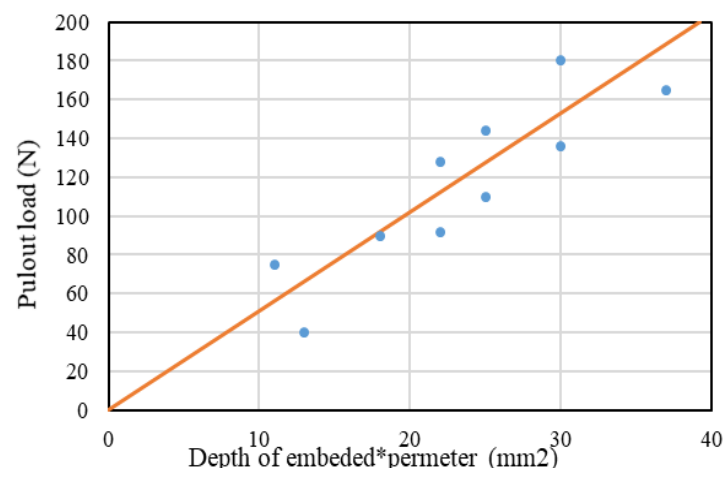

Fig. 11 Concrete with $1.0 \%$ steel fiber

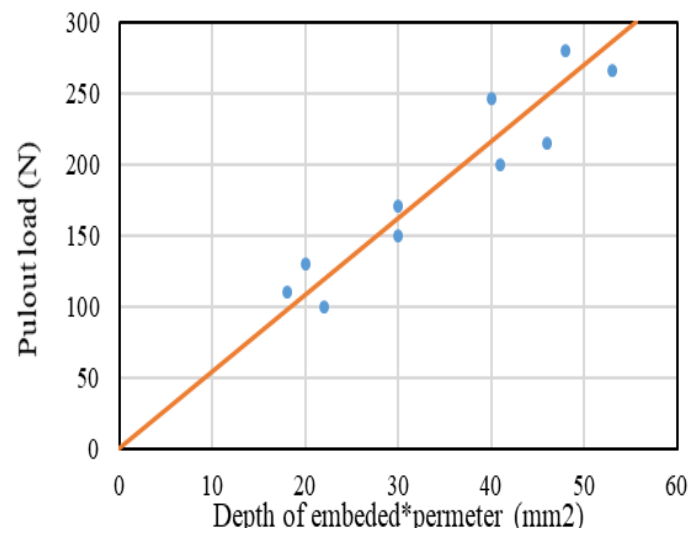

Fig. 12 Concrete with 1.5\% steel fiber

\section{COMPARISON BETWEEN EXPERIMENTAL RESULTS AND THEORETICAL PREDICTION}

As the ultimate bond strength Tu of the fibers is determined, the post-raking tensile strength $\sigma_{\mathrm{tu}}$ can be measured using Equation 19. The orientation factor $\xi_{0}$ was believed to be 0.33 in this analysis according to Romulad and Mandel [26], and $\zeta_{\mathrm{t}}$ was set to 0.5 since both specimens failed due to full pullout. $\sigma_{\mathrm{n}}$ 
Table 4 Test results and comparison with theoretical predictions

\begin{tabular}{|c|c|c|c|c|c|c|}
\hline \multirow{2}{*}{ 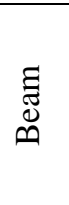 } & \multicolumn{2}{|c|}{$\begin{array}{l}\text { Ultimate } \\
\text { torque } \\
\mathrm{kNm} \\
\end{array}$} & \multirow{2}{*}{$\begin{array}{c}\mathrm{T}_{\mathrm{u}} \\
\text { test/ } \\
\mathrm{T}_{\mathrm{u}} \\
\text { cal. }\end{array}$} & \multicolumn{2}{|c|}{$\begin{array}{l}\text { Ultimate } \\
\text { twist } \\
\text { Deg./m }\end{array}$} & \multirow{2}{*}{$\begin{array}{c}\theta_{\mathrm{u}} \\
\text { test/ } \\
\theta_{\mathrm{u}} \\
\text { cal. }\end{array}$} \\
\hline & $\begin{array}{c}\mathrm{T}_{\mathrm{u}} \\
\text { test }\end{array}$ & $\begin{array}{c}\mathrm{T}_{\mathrm{u}} \\
\text { cal. }\end{array}$ & & $\begin{array}{c}\theta_{\mathrm{u}} \\
\text { test }\end{array}$ & $\begin{array}{r}\theta_{\mathrm{u}} \\
\text { cal. }\end{array}$ & \\
\hline B1 & 95 & 117 & 0.81 & 2.08 & 2.04 & 1.2 \\
\hline B6 & 106 & 114 & 0.87 & 2.56 & 3.12 & 0.82 \\
\hline B11 & 133 & 156 & 0.85 & 3.67 & 3.86 & 0.95 \\
\hline B16 & 147 & 156 & 0.94 & 4.45 & 5.17 & 0.86 \\
\hline B5 & 70 & 80 & 0.88 & 0.78 & 0.75 & 1.04 \\
\hline B10 & 88 & 83 & 1.06 & 0.88 & 0.82 & 1.07 \\
\hline B15 & 105 & 97 & 1.08 & 1.36 & 1.49 & 0.91 \\
\hline B20 & 115 & 104 & 1.10 & 1.63 & 1.85 & 0.88 \\
\hline
\end{tabular}

Fig. 13 presents a curve comparison between the results of the test and the theoretical results for the beams, where the - the curves reflect the relationship. The theoretical ultimate torque $\left(\mathrm{T}_{\mathrm{u} \text { cal }}\right)$ and ultimate angle of the twist and a comparison of the results with the experimental results are presented in Table (4). It may be seen in the image below that the theoretical results were in fairly good agreement with the experimental results. The ratio (Tu test)/(Tu cal) ranged from 0.81 to 1.1, with an average of 0.95 . Similarly, the ratio $(\theta u$ test $) /(\theta u$ cal $)$ varied from 0.82 to 1.07 , with an average of 0.94 .
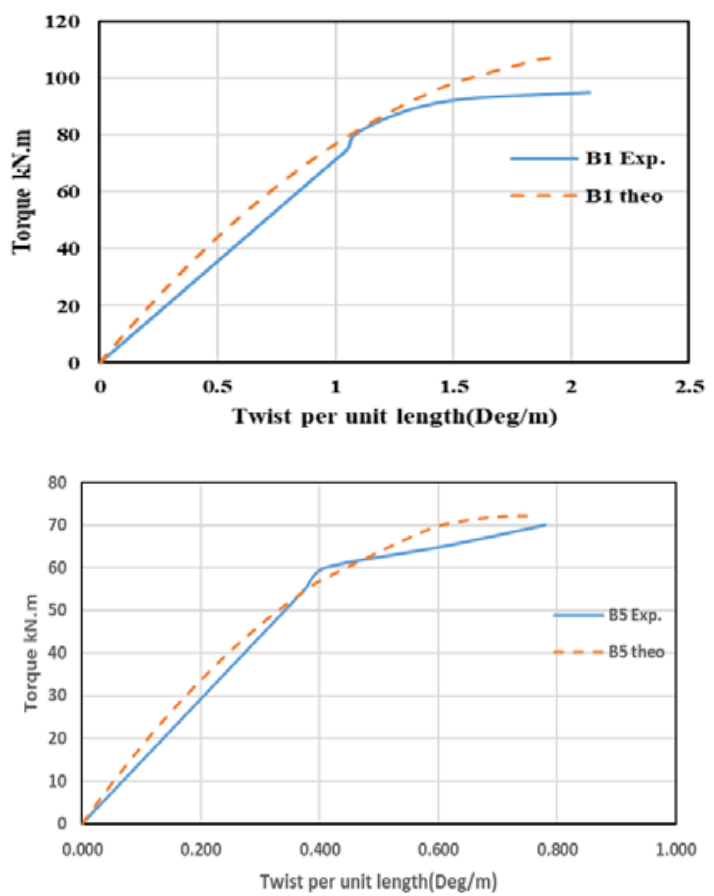

Fig. 13 Torque-twist curves for specimens in Groups A and B
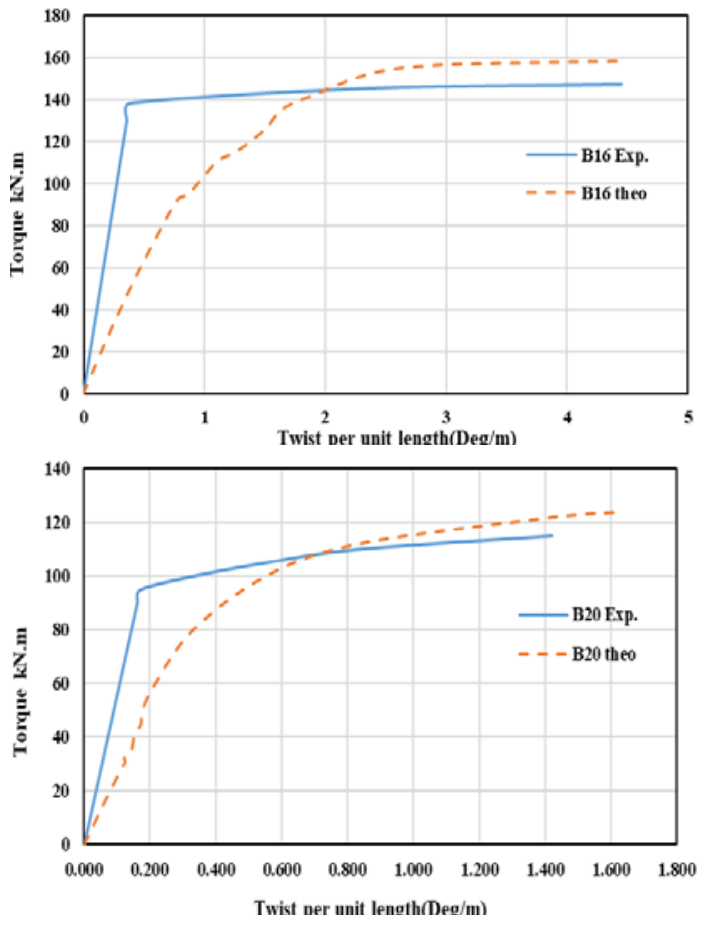

Fig. 13 Torque-twist curves for specimens in Groups A and B

\section{CONCLUSION}

In this study, the effect of short steel fibers on the behavior of reinforced concrete beams made from recycled aggregates under torsion was investigated experimentally. The results showed that adding steel fibers to concrete that contained normal aggregates led to an increase in the cracking strength and the torsional ultimate strength, but there was a slight effect on the torsional stiffness and the ductility of the beam. Adding steel fibers in concrete coating of recycled aggregates led to an obvious improvement in torsion. In general, using steel fibers in concrete with recycled aggregates causes percentage increases in the cracking strength and ultimate strength, and the effect of steel fibers is greatest in concrete containing recycled aggregates. The crack width of the beams with recycled aggregates was larger than that of the beams with natural aggregates. Adding $1.5 \%$ steel fibers in the concrete mix resulted in a smaller crack width than concrete without steel fibers

The other aim of the research was to analytically predict the complete torsional response of such beams. The softened truss model was considered by assuming a stress-strain relationship for fibrous recycled concrete in direct tension. The theory made reasonably good predictions of the torque-twist response of the tested beams. 


\section{REFERENCES}

[1] ACI Committee 544, State-of-the-art on fiber reinforced concrete. ACI manual of concrete practice. Farmington Hills (MI): American Concrete Institute; 1998.

[2] ACI Committee 544, Design considerations for steel fiber reinforced concrete. ACI manual of concrete practice. Farmington Hills (MI): American Concrete Institute; 1999.

[3] Chengdong S. and Haixiao L., Mechanical performances of steel fiber reinforced high strength concrete disc under cyclic loading. Construction and Building Materials, (146):2017, pp.276-282.

[4] Biao L., Lihua X., Yin C., Biao H. and Changning L., Experimental investigation on the stress-strain behavior of steel fiber reinforced concrete subjected to uniaxial cyclic compression. Construction and Building Materials, (140), 2017, pp.109-118.

[5] Oldrich S., Malgorzata P., Tomasz P. and Petr K., Identification of mechanical and fracture properties of self-compacting concrete beams with different types of steel fibers using inverse analysis. Construction and Building Materials, (138), 2017, pp.263-275.

[6] Song P. and Hwang S., Mechanical properties of high-strength steel fiberreinforced concrete. Constr Build Mater, 2004;18(9):pp.669-73.

[7] Mohammadi Y., Singh S. and Kaushik S. Properties of steel fibrous concrete containing mixed fibres in fresh and hardened state. Constr Build Mater, 2008; 22:pp.956-65.

[8] Cucchiara C., Mendola L and Papia M. Effectiveness of stirrups and steel fibres as shear reinforcement. Cement Concrete Comp, 2004;26:pp.777-86.

[9] Rao T. and Seshu D., Analytical model for the torsional response of steel fiber reinforced concrete members under pure torsion. Cement Concr Compos, 2005;27(4):pp.493-501.

[10] Engin S., Torsional behaviour of steel fiber reinforced concrete beams. MSc thesis, Department of Civil Engineering, Faculty of Engineering, Kocaeli University; 2005.

[11] Rao T. and Seshu D. Torsion of steel fiber reinforced concrete members. Cem Concr Res , 2003;33(11):pp.1783-1788.

[12] Juarez C. and Valdez P., Duran A, Sobolev K. The diagonal tension behavior of fiber reinforced concrete beams. Cement Concrete Comp, 2007; 29:pp.402-408.

[13] Li, C., Zhao, M., Zhang, X., Li, J., Li, X. and Zhao, M., Effect of Steel Fiber Content on Shear Behavior of Reinforced Expanded-Shale Lightweight Concrete Beams with Stirrups. Materials 2021, 14, 1107, pp. 1-13.
[14] Rao T. and Seshu D. Analytical model for the torsional response of steel fiber reinforced concrete members under pure torsion. Cement Concrete Comp, 2005; 27:pp.493-501.

[15] Karayannis C., Nonlinear analysis and tests of steel-fiber concrete beams in torsion. Struct Eng, Mech, 2000;9(4):pp.323-38.

[16] Karayannis C. and Chalioris C. Influence of steel-fibers on the capacity of flanged beams in torsion. Technika Chronika I, Sci J Tech Chamb Greece, 2000;20(2):pp.111-122.

[17] Nixon P., Recycled Concrete As an Aggregate for Concrete-A Review. Materials and Structures, 1977, Vol. 65, pp. 371-378.

[18] Ryu, J., An experimental study on the effect of recycled aggregate on concrete properties. Magazine of Concrete Research,2002; 45(1): pp.7-12.

[19] NP EN 1097-6. Test for mechanical and physical properties of aggregates. Part 6: Determination of particle density and water absorption, IPQ, Lisbon, Portugal; 2013.

[20] Padmini A. K., Ramamurthy K. and Mathews M. S. Influence of Parent Concrete on the Properties of Recycled Aggregate Concrete Construction and Building Materials, Vol. 23,2002; pp. 829-863.

[21] Topcu I. B. and Sengel S. Properties of Concrete Produced with Waste Concrete Aggregate Cement and Concrete Research, Vol. 34,2004; pp. 1307-1312.

[22] Tsung Y. T., Yuen Y., and Chao L.H. Properties of HPC with Recycled Aggregates Cement and Concrete Research, Vol.36,2006; pp. 943-950.

[23] Hsu C., Softened Truss Model Theory for Shear and Torsion. Research Report No. UHCE-86-9, University of Houston, Aug. 1986, 63 pp.

[27] Lim, T., Paramasiva P., Mansur, M. A. and Lee S. L., Tensile behavior of steel fiber reinforced cement composite, Proceedings, $3^{\text {rd }}$ RILEM International Symposium on Developments in Fiber Renforced Cement and Concrete, University of Sheffield, July, 1986, pp. 7-16.

[28] B.S. 882, British Standard Specification for Aggregates from Natural Sources for Concrete.1983,pp.1-34.

[29] Romualdi P., and Mandel A., Tensile Strength of Concrete Affected by Uniformly Distributed and Closely Spaced Short Lengths of Wire Reinforcement," ACI Journal, Proceedings, 61(1),1964, pp.657-672.

Copyright (C) Int. J. of GEOMATE All rights reserved, including making copies unless permission is obtained from the copyright proprietors. 